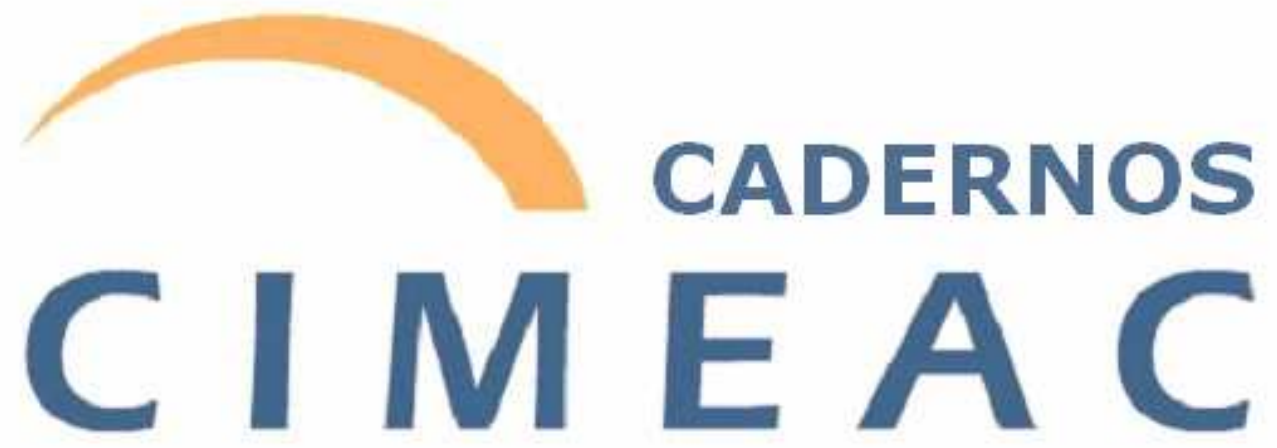

Ribeirão Preto, v. 02, n. 01, 2012.

ISSN 2178-9770 


\section{INTRODUÇÃO / INTRODUCTION}

Com a publicação deste segundo volume, a revista Cadernos CIMEAC inaugura com bastante satisfação seu segundo ano de trabalhos. Aqueles que, de alguma forma, se engajam nos esforços em educação popular bem sabem o quanto pode ser penosa a atividade na área - vide o sem-número de dificuldades de obtenção de recursos, por exemplo, para a compra de material; a absoluta falta de espaço para a formação/manutenção de uma escola; a carência de recursos para custear alugueis e taxas afins etc. É justamente à luz dessas dificuldades que o sucesso na publicação de uma revista semestral oferece um contraste animador para a paisagem por vezes pálida da educação popular.

O presente número significa um momento extremamente importante para este nosso espaço de discussão: é a primeira edição da revista que conta, exclusivamente, com a colaboração de autores não-vinculados ao Centro de Investigações de Metodologias Educacionais Alternativas Conexão. As temáticas abordadas, ademais, enriquecem bastante a proposta da revista, já que colocam, em diversos matizes, questões fundamentais para o pensamento contemporâneo em educação. Destacamos, de partida, a entrevista gentilmente concedida ao CIMEAC pelo professor Michel Onfray - filósofo francês, autor de inúmeras obras já traduzidas em diversos países, fundador da Universidade Popular de Caen em 2002. Nesta entrevista (toda realizada em francês, de modo que se encontra publicada, aqui, em formato bilíngue - português-francês), Onfray discute as principais orientações que deram forma e sentido a uma Universidade popular na França, articulando a experiência prática (afinal, a UP de Caen festeja uma década de existência em 2012!) com a reflexão teórica de um pensamento autointitulado "libertário". Agradecemos, ainda, a importante colaboração de Carlos Augusto Rodrigues na tradução do texto para o português.

Abrindo a seção de artigos, o professor Mauro lasi (UFRJ, Núcleo de Educação Popular 13 de Maio) - autor que gentilmente aceitou o convite para publicação neste número -, em conferência realizada na UFSC e publicada pela primeira vez na revista Universidade e Sociedade - ANDES (n. 48, ano XXI, julho de 2011), retoma o problema da "consciência" nas obras de Marx e Engels (discutindo com autores centrais do pensamento marxista - Lenin, Lukács, Sartre etc.) no 
sentido de pensar, à luz do presente brasileiro, as possibilidades e os limites da educação no pensamento de esquerda. Saindo um pouco desse terreno áspero de toda essa importante discussão teórica e política sobre a "fragmentação" da esquerda, o texto de Priscilla Amaral destaca alguns aspectos do ensinoaprendizagem do teatro nas salas de aula, enfatizando o "fazer artístico" como elemento fundamental para o aprofundamento do trabalho das diversas linguagens na sala de aula (retomando, portanto, uma discussão atinente aos próprios PCN). Os três artigos seguintes foram enviados por professoras-pesquisadoras de Roraima que tiveram contato com parte do grupo do CIMEAC em um curso ministrado por Genaro A. Fonseca e Danilo Seithi Kato na UNESP de Araraquara (em outubro de 2011). O primeiro texto, escrito por Ana Célia de Oliveira Paz, discute a formação profissional do gestor escolar no sentido de fundamentar a administração da escola em matrizes democráticas. As duas últimas contribuições versam sobre práticas de leitura nas salas de aula: Lysne Nôzenir de Lima apresenta alguns pontos de um projeto de sala de leitura desenvolvido em uma escola de ensino fundamental na periferia de Boa Vista (Roraima) - o objetivo é, "por meio de um professor capacitado que deverá realizar atividades de leitura", construir possibilidades para o desenvolvimento da criatividade e do pensamento lógico, além do incentivo ao hábito da leitura aos estudantes por meio de ações realizadas "em parceria com todos os professores, oportunizando assim o fortalecimento e integração no processo de ensino aprendizagem"; Simone Refkalefsky Varela discute os resultados de uma pesquisa feita junto a uma escola da rede pública de Boa Vista sobre a prática da leitura, entrelaçando a prática de formação de jovens leitores e as propostas dos PCN.

Agradecemos, portanto, a todos os autores, leitores e colaboradores, na esperança de que esta edição amplie a discussão em educação popular.

Ribeirão Preto, janeiro de 2012.

Os Editores 


\section{ÍNDICE DESTE NÚMERO / INDEX - CURRENT ISSUE}

\section{ENTREVISTA / INTERVIEW}

EDUCAÇÃO, LIBERTAÇÃO DE SI / EDUCATION, LIBERATION DE SOI 05 Entrevista com Michel Onfray / Entretien avec Michel Onfray

\section{ARTIGOS / ARTICLES}

EDUCAÇÃO, CONSCIÊNCIA DE CLASSE E ESTRATÉGIA REVOLUCIONÁRIA.

Mauro lasi

O FAZER NO TEATRO E O FAZER NA AULA DE TEATRO

Priscilla Amaral

A FORMAÇÃO PROFISSIONAL DO GESTOR ESCOLAR: ALICERCE

PARA UMA POSTURA VERDADEIRAMENTE DEMOCRÁTICA.

Ana Célia de Oliveira Paz

PROPOSTA DE IMPLEMENTAÇÃO DA SALA DE LEITURA: VISANDO

O DESENVOLVIMENTO PARA A FORMAÇÃO DE CIDADÃOS CRÍTICOS.

Lysne Nôzenir de Lima

LEITURA: IMPORTÂNCIA DE DESPERTAR E DESENVOLVER O GOSTO PELO HÁBITO DA LEITURA NOS ANOS INCIAIS DO ENSINO FUNDAMENTAL EM UMA ESCOLA PÚBLICA DE BOA VISTA/RR 58

Simone Refkalefsky Varela 